\title{
Modeling of Variable Speed Drive in the Control System Laboratory at the Electrical Department of State Polytechnic of Sriwijaya
}

\author{
Siswandi Siswandi ${ }^{1, *}$ Anton Firmansyah ${ }^{1}$ Destra Andika Pratama $^{1}$ Yessi Marniati $^{1}$ \\ Muhammad Irsyad Abdulah ${ }^{1}$ Muhammad Irfan Pratama ${ }^{1}$ Ichwaldi Amzah $^{2}$ \\ ${ }^{1}$ Politeknik Negeri Sriwijaya, Jl. Srijaya Negara - Kota Palembang, 30139 \\ ${ }^{2}$ Politeknik Mukah Sarawak, KM 7.5, Jalan Oya 96400 Mukah Sarawak, Malaysia \\ ${ }^{*}$ Corresponding author. Email: c.siswandi@yahoo.co.id
}

\begin{abstract}
Induction motors are the most widely used motors currently, because they have a simple construction, are relatively inexpensive, lighter and have high efficiency with an easy to maintain compared to DC Motors. However, in terms of setting the speed and torque of an induction motor it is not an easy problem to do, with the development of control system technology, one way to do this is to use a three-phase VSD (Variable Speed Drive) Inverter to adjust the frequency in order to change the speed of the three-phase induction motor. The inverter converts a constant $\mathrm{AC}$ voltage source into an AC voltage source whose frequency can be adjusted between 0-150 Hz. In this study the authors will use the Matlab-Simulink simulation to prove the workings of the VSD (Variable Speed Drive) and AC Motor.
\end{abstract}

Keywords: VSD (Variable Speed Drive), AC Motor, Matlab-Simulink

\section{INTRODUCTION}

Some production processes are still being studied more deeply through the application of the principles of clean production to obtain energy efficiency which will directly have an impact on reducing production costs and increasing profits for the Cement Industry.

One form of efficiency that will be carried out is the migration of the inlet vane control to speed control Fan Motor by implementing the installation of a Variable Speed Drive (VSD).

Fan Motor is one of the main equipment in the process of making/processing materials in the form of limestone, clay, iron sand, \& silica sand into raw meal as feed/feeding kiln. Where this Fan Motor works as a fan to pull/lift fine materials in the raw mill machine which will then be distributed to the CF silo through transportation in the form of fluxo slides \& bucket elevators.

Along with technological developments, the air volume setting on the fan that originally used the inlet vane control can be changed to speed control using a Variable Speed Drive (VSD). Where one of the main considerations for using VSD is the difference in power consumption using inlet vane control \& using VSD and supporting efficiency programs.

\section{REVIEW OF LITERATURE}

Induction motors generally rotate at a constant speed, close to their synchronous speed. However, for certain uses, rotation settings are also desired. Setting the rotation of the induction motor requires a rather high cost. Usually this setting can be done in several ways as follows [2]:

a) Change the number of poles.

Since $n s=120 \mathrm{f} / \mathrm{p}$, a change in the number of poles (p) or frequency (f) will affect the rotation. The number of poles can be changed by planning the stator windings in such a way that it can accept incoming voltages at different winding positions. Usually two changes in synchronous speed are obtained by changing the number of poles.

b) Changing the frequency of the lines

Setting the frequency to control the rotation of the induction motor is usually followed by setting the input 
voltage which is proportional to the frequency. By using an inverter, which is a device that can convert direct voltage into alternating voltage, the resulting frequency can be changed. The change in the frequency of the alternating current of this inverter is determined by the period of the pulse that triggers the rectifier, the frequency and also the speed can be adjusted. The basic concept of a frequency converter is to convert an AC power source to DC through a controlled rectifier or not and then convert it back into AC to provide a voltage to the motor that can be adjusted for the amount of voltage and frequency [2].

\section{c) Regulating the grid voltage}

From the motor coupling equation above, it is known that the coupling is proportional to the square of the applied voltage. For the load characteristics as shown in Figure 1, the speed will change from 1 to 2 for the initial half-voltage input voltage. This method only produces a limited rotation setting (narrow setting area) [2].

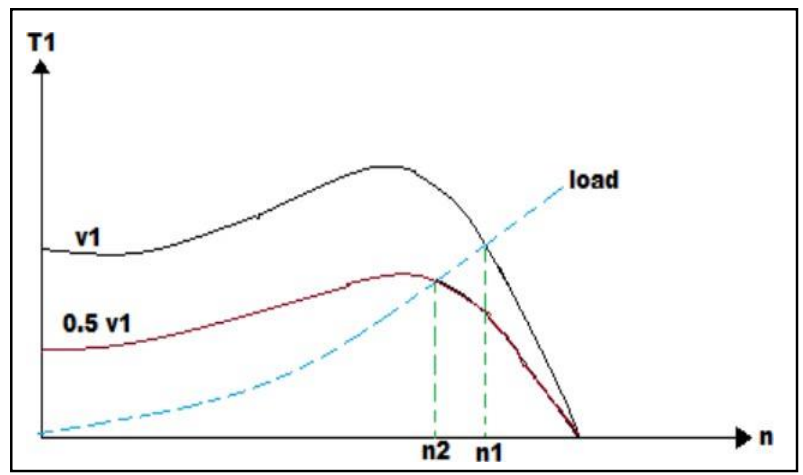

Figure 1. Grid Voltage Graph [2]

d) Arrangement of external resistance.

The external resistance of the winding rotor induction motor can be adjusted, thereby producing different speed coupling.

\subsection{Variable Speed Drive (VSD)}

Variable Speed Drive or VSD is a device used to control the speed of an electric motor (AC) by controlling the frequency of the electric power supplied to the motor [6]. The VSD controls the speed of the induction motor by changing the frequency of the grid to an adjustable value on the machine side thus enabling the electric motor to quickly and easily adjust the speed to the desired value [3]. The two main functions of a Variable Speed Drive are to perform the conversion of electricity from one frequency to another, and to control the output frequency.
The circuit in the VSD generally consists of a rectifier, DC link, inverter and control drivers. The circuit diagram of the VSD is as shown in Figure 2.

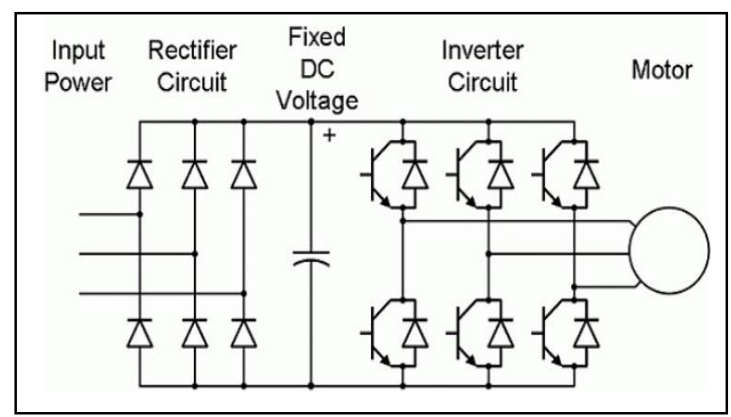

Figure 2. VSD circuit diagram [3]

\subsection{Inverter}

The inverter functions to convert direct voltage (DC) into alternating voltage (AC) with an electronic switching system so that the resulting alternating voltage can be adjusted for amplitude and frequency as shown in Figure 3.
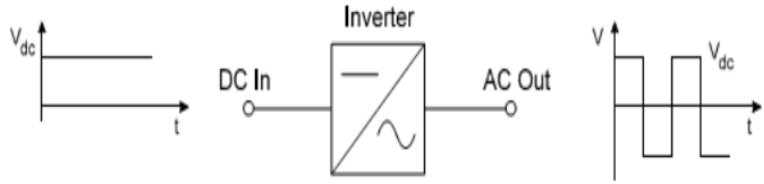

Figure 3. Inverter us converter [3]

The 3-phase inverter can be seen in Figure 3 where the output voltage is without PWM (six-step).

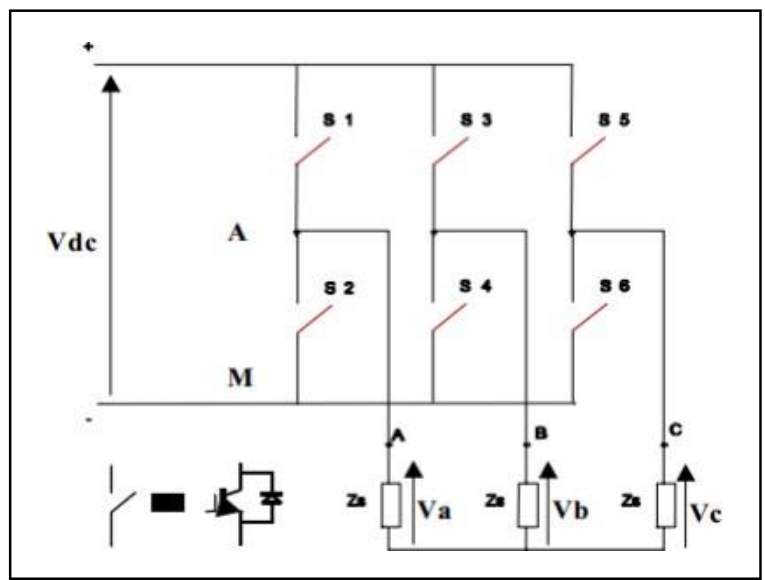

Figure 4 Inverter 3 fasa [3]

In this study, the inverter used is a 3-phase inverter with a switching component, namely Insulated Gate Bipolar Transistor (IGBT) with a snubber resistance value $(\mathrm{Rs})=10000 \mathrm{Ohms}$, snubber capacitance $(\mathrm{Cs})=\mathrm{inf}$ to obtain a resistive snubber, internal resistance device selected $($ Ron $)=1 \mathrm{e}-3 \mathrm{Ohms}$, and the forward voltage is 1.4 Volts. Three-phase inverter modeling in MATLAB can be seen in Figure 5 and the input parameter blocks can be seen in Figure 6 . 


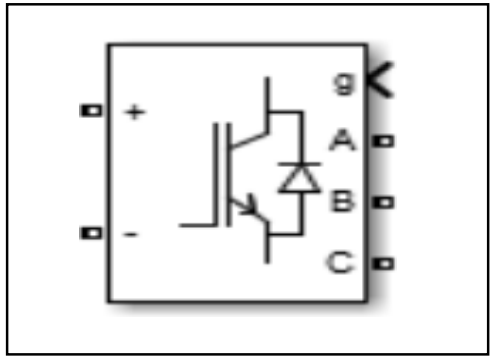

Figure 5 Inverter Modelling

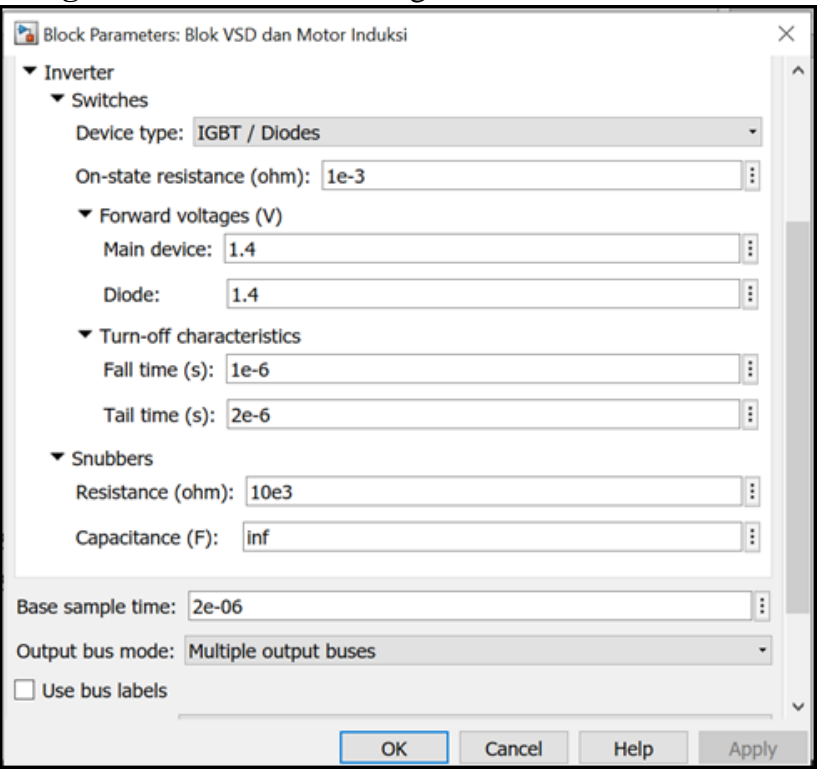

Figure 6 Blok Parameter Inverter 3-phase

\subsection{Speed Controller.}

In the speed controller, the speed of the motor is controlled. By using a speed detector such as a tachometer or encoder. The instrument provides feedback to the speed controller. The speed controller circuit in the form of PI gain is shown in Figure 7

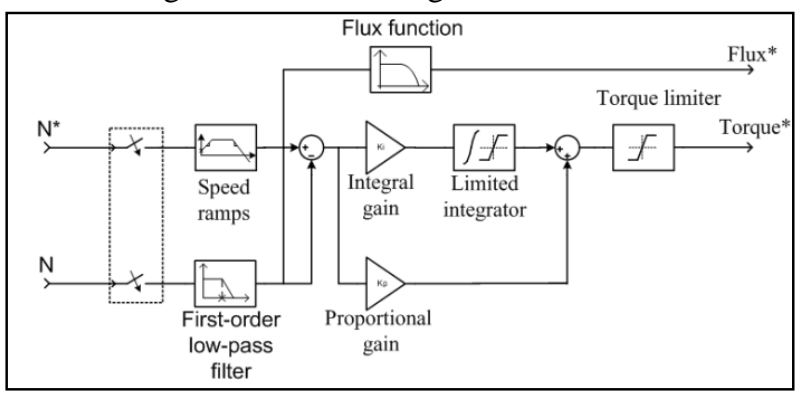

Figure 7 Speed Controller [10]

Integral proportional controller (PI) is a combination of functions of proportional and integral controller. This merger aims to cover the lack of proportional controller (P) which is relatively slow in response. Meanwhile, the $\mathrm{P}$ controller is still used to maintain that the controller can respond even for a small difference.

\subsection{MatLab and Simulink.}

MatLab (Matrix Laboratory) is a programming language developed by The MathworksTM.Inc. This language is widely used for engineering numerical calculations, computation, symbolic, visualization, graphics, mathematical data analysis, statistics, simulation, modeling, and GUI design. While simulink is a block diagram that is used to model and simulate dynamic systems such as control, signal processing, and communication [18].

MatLab is a very good software to be used to analyze various needs in the engineering field. In MatLab there are two important parts, namely the matlab editor which functions to write listings the program and the simulink used to perform the simulation. By using simulink, which is an integral part of the program, we can model a control system or a plant to be regulated. It can be designed using the available blocks and setting parameters will be easier. Simulink blocks can also be formed from mathematical equations using transfer blocks function so that we can write the equations in the block according to the parameters we are looking for.

In MatLab there is a window which is the parent window that covers the entire MatLab working environment. In previous versions, this window specifically did not exist but was integrated with the command window. There is no main function offered by this window other than as a docking place for other forms.

\subsection{MatLab and Simulink.}

The cement industry is the dominant market for industrial fans. Fans in the cement industry are heavy duty fans and operate on 2 main functions, namely as air supply or exhaust gas exhaust and material carrier. There are many types of process fans used in the cement industry such as Raw Mill Fans, Cooling Fans, Induced Draft Fans (ID Fans), Booster Fans, Coal Mill Fans and Cooler Exhaust Fans.

Fan Motor is one of the main equipment in the process of making/milling materials in the form of limestone, clay, iron sand, \& silica sand into raw meal as a feed/feeding kiln. Where this Fan Motor functions as a fan to pull/lift fine materials in the raw mill machine which will then be channeled to the CF silo via transport in the form of fluxo slides and bucket elevators. Fan Motor is the fan with the largest power in the Cement Industry with the installed power of this fan motor is $3700 \mathrm{KW}$. The operational pattern of this fan is to regulate flow using the inlet damper and start using a liquid starter.

Along with technological developments, the air volume setting on the fan that originally used the inlet vane control can be changed to speed control using a 
Variable Speed Drive (VSD). Where one of the main considerations for using VSD is the difference in power consumption using inlet vane control \& using VSD as well as supporting the Cement Industry efficiency program to reduce energy costs. The use of an air flow regulation application with inlet vane control causes the Fan Motor motor power consumption to be quite high when compared to using a Variable Speed Drive because the air flow setting is done by opening/closing the damper, but the electric motor operates at maximum speed, while using a Variable Speed Drive setting Air flow is done by reducing the speed of the electric motor, which means it also reduces the power consumed by the electric motor. The high power consumption of electric motors contributes to an increase in the index of electrical energy use in the Raw Mill System.

The topology of the VSD used can be depicted in Figure 8 as follows.

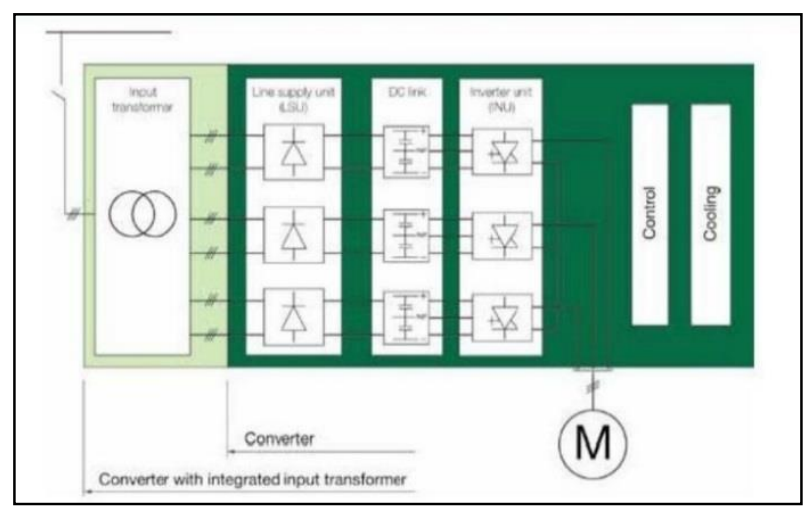

Figure 8 ACS 5000 Voltage Source Inverter Multilevel Fuseless Topology

Variable Speed Drive or VSD is a control device that is used to adjust the rotational speed of an AC motor so that it can rotate at the desired speed. The VSD used in the Cement Industry is the ABB brand, type ACS500. By using simulink in the MATLAB R2018b software, the VSD can be modeled as shown in Figure 9 below:

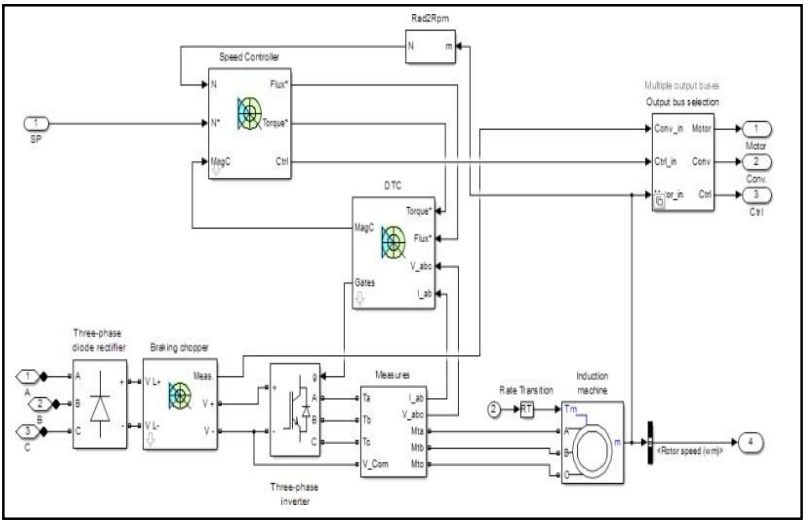

Figure 9 VSD Modelling

\section{METHOD}

The type of research carried out is quantitative research by processing parameter data obtained through the design of the initial design simulation model and the system conditions are made as close as possible to the actual conditions. This study was conducted to show the actual condition of the Fan Motor induction motor which is speed controlled using a Variable Speed Drive (VSD) based on data. This system modeling is useful for knowing and understanding the working principle of VSD in controlling the speed of a three-phase induction motor.

The stages such as the flow chart Figure 3.1 that will be carried out in the implementation of this research so that the results achieved do not deviate from the predetermined goals, namely:

1. Collecting induction motor speed data, electric current value, electric voltage, power factor value or cos phi, induction motor and exhaust fan specification data, pulley diameter size, air velocity value produced by exhaust fan and air velocity in ventilation holes, ventilation size, space and exhaust gas flow rate data for each engine.

2. Calculate the air flow in the fan chimney from the fan blade speed data and fan specifications and calculate the induction motor's electrical power consumption and the induction motor's shaft speed from electrical data and induction motor data.

3. Perform calculations with different variables referring to several values of the diesel engine Exhaust Gas flow rate so that the probability of the relationship between the variable speed drive frequency values, induction motor input power, motor speed, exhaust fan speed and the resulting air flow is obtained.

4. Perform simulations using computer applications or programs in this case simulation using Simulink Matlab software and validation calculations using the Matlab script code.

5. All calculation results are compared with validation results using the matlab code script and simulation using simulink.

6. Review using the right reference if there is a difference in the value of the calculation results and validation or simulation.

7. Provide conclusions from all the results obtained. 


\section{MEASUREMENT DATA}

This measurement data is obtained from Actual Testing and Matlab Simulink

Table 1 Simulation results of VSD frequency changes on Actual Tests and Matlab Simulink

\begin{tabular}{|l|l|l|l|l|}
\hline $\begin{array}{l}\text { Set } \\
\text { point }\end{array}$ & $\begin{array}{l}\text { Field } \\
\text { Frequency } \\
(\text { Hz) }\end{array}$ & $\begin{array}{l}\text { Field } \\
\text { Speed } \\
(\text { rpm })\end{array}$ & $\begin{array}{l}\text { Simulation } \\
\text { Frequency } \\
(\text { Hz) }\end{array}$ & $\begin{array}{l}\text { Simulation } \\
\text { Speed } \\
(\text { rpm })\end{array}$ \\
\hline 1 & $\mathbf{0 . 3 4 9}$ & 69.6 & $\mathbf{0 3 . 4 9}$ & 69.83 \\
\hline 2 & 17.35 & 348 & 17.45 & 349 \\
\hline 3 & 29.02 & 577.8 & 29.02 & 580.4 \\
\hline 4 & 32.53 & 647.4 & 32,53 & 650.6 \\
\hline 5 & 34.60 & 689.2 & 34.60 & 692 \\
\hline
\end{tabular}

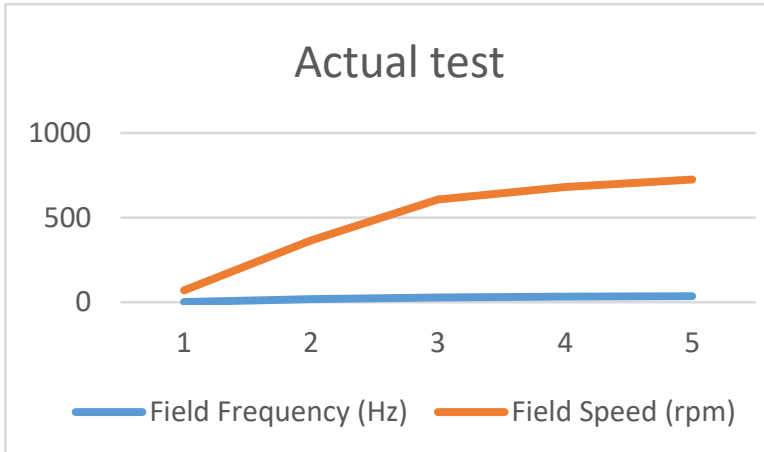

Figure 10. Graphic from table 1Actual test

Figure 10 actual testing From the table above at a frequency of $03.49 \mathrm{~Hz}$, the motor speed is $69.36 \mathrm{rpm}$ and continues to increase to $34.60 \mathrm{~Hz}$ with a speed of 689.2 rpm for five set points.

Furthermore, after doing research using simulink, it is obtained we can get some result and then graph image 4.2 simulink test.

In figure 10. actual testing From the table above at a frequency of $03.49 \mathrm{~Hz}$, the motor speed is $69.36 \mathrm{rpm}$ and continues to increase to $34.60 \mathrm{~Hz}$ with a speed of 689.2 rpm for five set points.

Furthermore, after doing research using simulink, it is obtained we can get some result and then figure 11 . simulink test.

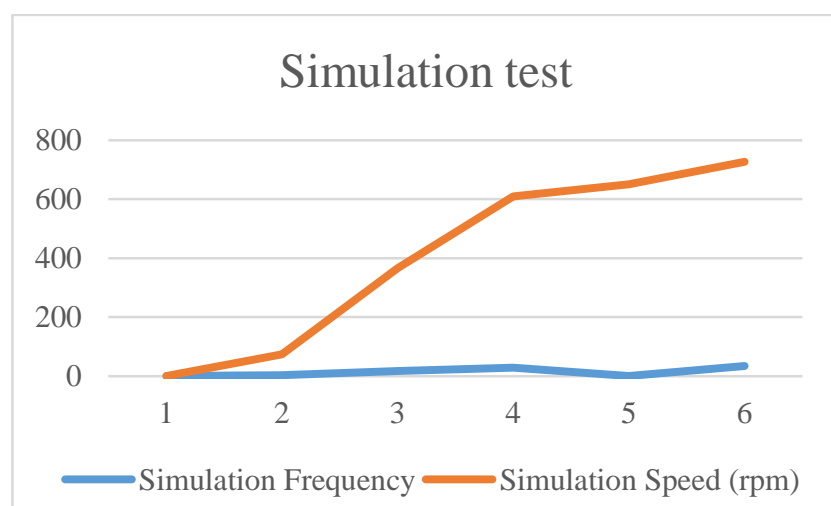

Figure 11. Simulation test
The speed measured in Matlab Simulink is $69.83 \mathrm{rpm}$ with a simulated frequency of $03.49 \mathrm{~Hz}$. At the second setpoint, which is $17.45 \mathrm{~Hz}$, the motor speed measured in Matlab Simulink is $349 \mathrm{rpm}$. For the third setpoint, which is $29.02 \mathrm{~Hz}$, the motor speed measured in Matlab Simulink is $580.4 \mathrm{rpm}$. Then the fourth setpoint is $32.53 \mathrm{~Hz}$, the motor speed measured in Matlab Simulink is $650.6 \mathrm{rpm}$. While the fifth setpoint is 34.60 $\mathrm{Hz}$, the motor speed measured in Matlab Simulink is 692 rpm

\section{CONCLUSION}

The Matlab application, in its application to the VSD modeling that has been done, can help users to find out the shape of the graph, the location of the error, the minimum and maximum capacity of the designed system.

Validation of the VSD modeling test results on matlab simulink by changing the setpoint of the load frequency of a 3-phase induction motor $600 \mathrm{~V}, 42 \mathrm{~Hz}$, $840 \mathrm{rpm}$ by changing the frequency value from minimum to maximum, it is found that the magnitude of the frequency change is directly proportional to the magnitude of the change in motor rotational speed and has an average value. The average error is larger, but in fact Simulink has imperfect speed results.

The results of VSD modeling to adjust the speed of an induction motor with a setpoint input frequency can be used as a reference to determine the maximum ability of the motor rotation when given the maximum frequency

\section{REFERENCES}

[1] W. L. A. de Almeida, P. Bertoldi, Energy Efficiency Improvements in Electric Motors and Drives. Berlin: Springer-Verlag, 1997.

[2] J. Argandhi, “Analisa Pengasutan Soft Starter Motor Induksi 3 Fasa,"

eprints.polsri, vol. 2014, no. June, pp. 1-2, 2014.

[3] M. Barnes, Variable Speed Drives and Power Electronics. Perth, Australia: Elsevier, 2003.

[4] T. Wildi, "Electrical Machines, Drives, and Power Systems," PhD Propos., vol. 1, p. 886, 2002.

[5] M. H. Rashid, Elektronika Daya: Rangkaian, Defais, dan Aplikasinya. Jakarta: Prenhallindo, 1999.

[6] E. C. Lister, Mesin dan Rangkaian Listrik. Jakarta: Erlangga, 2018.

[7] M. Pemberton, "Variable speed pumping: Myths and legends," World Pumps, vol. 2005, no. 460. pp. 22-24, 2005, doi: 10.1016/S0262- 1762(05)004529. 
[8] P. Tabah, R. M. Francis, M. Belajar, S. Elektronika, and $T$. Guru, "elektronikadasar.web.id/komponen/sensor-tranducer/sensor resistor/,diakses tanggal 19-01-2015," vol. 3, no. Juli 1982, p. 2015, 2015.

[9] B. Theraja, A Text Book of Electrical Technology, vol. I, no. I. New Delhi: Nirja Construction and Development Co (P) Ltd, 1986.
[10] U.S. Department of Energy: Industrial Technologies Program, "Improving Motor and Drive System Performance :," Ind. Technol. Progr., pp. 3, 45, 46, 2008.

[11] Zuhal (Zhanggischan), Prinsip Dasar Elektroteknik. Jakarta: Gramedia Pustaka Utama, 2004. 